Metodološki zvezki, Vol. 6, No. 1, 2009, 1-26

\title{
Private Household Concepts and their Operationalisation in Cross-National Social Surveys
}

\author{
Juergen H.P. Hoffmeyer-Zlotnik ${ }^{1}$ and Uwe Warner ${ }^{2}$
}

\begin{abstract}
Starting with the input-harmonised and methodically controlled European Social Survey (ESS), moving on to the national censuses, and then turning our attention to the three groups participating in surveys (researchers, interviewers and respondents), we discover that the private household concept is defined in many different ways. Each of these definitions entails a different household composition. Using an example, we demonstrate how different definitions of private household (and different household compositions) affect the socio-economic status and income of the household. Ultimately, a variation in the definition of private household is enough to raise or lower the national poverty line.

Our findings lead us to propose that "private household" be operationalised across countries in a way that guarantees that persons can be unequivocally assigned to households on the basis of inclusion and exclusion criteria.
\end{abstract}

\section{Introduction}

A country's operational definition of the private household concept is shaped by its national culture. Each definition embodies a particular structure, and different definitions lead in turn to different structures with different compositions of the group definable as a household and, thus, to different private household sizes.

The definition of household - and the resultant variation in household size - is indeed relevant when the analysis focuses on the social structure in which the individual is embedded. This is particularly evident when the aim is to measure sociological variables on which the defined composition of private household has a significant effect:

\footnotetext{
${ }^{1}$ GESIS - Leibniz-Institute for the Social Sciences, Mannheim, Germany

${ }^{2}$ CEPS/INSTEAD, Differdange/Luxembourg
} 
- household income and

- socio-economic status (SES) of the household.

The composition of the private household plays a role with regard to household income since the latter can vary considerably depending on the number of persons who contribute to it and the composition of household income types in question. This cannot be corrected using equivalence income because if, in one case, a person with a high income and a person with a low income (e.g. father and son) constitute a household and, in another case, these two persons constitute two separate households, this leads, at the level of society, to different income distributions.

The problem is similar in the case of socio-economic status when the person in the private household with the highest status determines the status of the group as a whole.

If one takes a look at social surveys such as the International Social Survey Programme (ISSP) or the European Social Survey (ESS), one is struck by the fact that the participating countries define "private household" in very different ways. The different definitions of private household have considerable consequences, particularly in the case of the ESS because it is an input-harmonised survey and all participating countries are supposed to use the same definition. However, even the various versions of the questionnaire in countries with different linguistic groups do not use the same definition. Therefore, standardisation is called for.

In the present paper we address the following questions:

- How do the national researchers of the ESS define the concept of private household?

- How do the statistical offices of different European countries define the concept of private household?

- What structure is behind the national definitions of private household?

- What influence do private households of different composition have on the household income, the SES of a private household?

- What should an attempt at harmonising the concept of private household for the purpose of international comparison look like?

\section{Definition of private household in the European Social Survey}

The ESS project instructions for interviewers provide the following explanation of the household concept:

"One person living alone or a group of people living at the same address (and have that address as their only or main residence), who either share at least one main meal a day or share the living accommodation (or both). 
Included are: people on holiday, away working or in hospital for less than 6 months; school-age children at boarding school; students sharing private accommodation.

Excluded are: people who have been away for 6 months or more, students away at university or college, temporary visitors."

(European Social Survey, 2002: Project Instructions (PAPI), p.11)

Assuming they read the project instructions, interviewers are aware of what household means in the context of the survey. However, respondents are not. They hear only the question and the interviewers are not supposed to give the definition unless the respondents so request. A closer look at the definition given in the project instructions reveals that it is that used by England's Statistical Office (Statistical Commission and Economic Commission for Europe et al., 2005, p.8). However, in the last two census rounds, even the English Statistical Office further reduced this definition to the common address, a criterion which in the 1991 round was still restricted by a general common-housekeeping criterion (United Kingdom, 1991). This was, however, no longer the case in 2001 (National Statistics, 2001). Apart from England, the criterion common meal is used only in the Greek definition (National Statistical Service of Greece, 2003). Even the criterion share the living accommodation as an accepted alternative to share one main meal a $d a y$, is a defining element only in a small number of countries.

In the participant countries' translations of the ESS questionnaire, household is defined as follows:

- In Germany, the household question reads:

"Wie viele Personen leben ständig in diesem Haushalt, Sie selbst eingeschlossen?

Denken Sie dabei bitte auch an alle im Haushalt lebenden Kinder."

- The German-speaking part of Switzerland uses its own translation of the blueprint:

"Wenn Sie sich selbst dazuzählen, wie viele Personen - Kinder eingeschlossen - leben regelmäßig als Mitglieder in Ihrem Haushalt?"

- The question is translated as follows in the French-speaking part of Switzerland:

"Combien de personnes, vous même et les enfants y compris, vivent régulièrement comme membres de votre ménage?"

- The Italian-speaking part of Switzerland uses the following wording:

"Quante persone, i bambini e Lei inclusi - vivono qui regolarmente, quali membri della Sua economia domestica?"

- In Italy, there is a different household definition behind the text of question F1: 
"Compresi Lei ed eventuali bambini, quante persone vivono regolarmente in questa casa come membri della famiglia?"

- Coming back to a German-language translation of the blueprint, we see that, in Luxembourg too, the wording used in Germany is not automatically adopted:

"Wie viele Personen leben ständig in diesem Haushalt, Sie selbst eingeschlossen?

Denken Sie dabei bitte auch an alle im Haushalt lebenden Kinder."

- Bilingual Luxembourg's French-language text is very similar to the French text used by trilingual Switzerland:

"Y compris vous-même - et vos enfants - combien de personnes vivent ici de façon régulière comme membres de votre ménage?"

- The Portuguese-language text for Luxembourg's largest minority reads:

"Incluindo-o(a) a si e aos seus filhos - quantas pessoas residem aqui de forma regular como membros do seu agregado?"

- Central elements of this text differ considerably from the wording used in Portugal itself :

"Contando consigo, quantas pessoas - incluindo crianças - vivem habitualmente nesta casa?

(Source: ESS1 Appendix A3_e6: Variables and Questions; ESS1-2002 Questionnaires and other fieldwork documents)

The instructions in the blueprint at least include a household definition, even if it is one which is not normally used in most of the participant countries. However, as a rule, if one looks for household definitions in the national interviewer instructions one is in for a disappointment:

- Germany: Explanations of individual variables are provided in the field instructions, however no household definition is given.

- Switzerland - German and French-speaking: No explanations of individual variables and, thus, no definition of household.

- Switzerland - Italian-speaking: No field instructions available.

- Luxembourg: Fieldwork instructions available only in French. No definition of household given.

- Portugal: Explanations of individual variables are provided in the "Instruções de apoio ao preenchimento do questionário". The following information is given on questions F1 to F4: "As perguntas F1, F2, F3 e F4 permitem identificar a composição do agregado familiar. Note que aqui as crianças devem ser incluídas ao contrário da folha de contacto onde só se referiam as pessoas com mais de 15 anos. Ou seja, pretende-se aqui identificar a idade, o sexo e a relação de parentesco de todas as pessoas que vivem no agregado familiar. Note ainda que em cada coluna se regista o laço familiar partindo do inquirido. Por exemplo, se a pessoa mais velha no lar é o pai da inquirida, ele deve constar na coluna 2 e deve ser registado 
como laço familiar na linha "pai/mãe...). Não devem ser incluídas nesta grelha as empregadas domésticas." (ESS1-2002, Portugal: Instruções, p. $10)$.

Respondents of the ESS are not provided with any proper clarification of the household definition. Household in the national surveys is given only by questionnaire's stimuli in terms of one dimension:

- household

- dwelling

- house

- economic unit

- family

Respondents are not provided with any proper clarification of the household definition. To a large extent, therefore, the interviewees are free to use their own definitions, unhindered by the interviewers.

Three German studies outlined in point 4.3 below show that both interviewers and respondents have their own definitions of private household which are determined partly by their personal situation and partly by their view of what constitutes a family. The spectrum of these subjective definitions is very broad.

\section{Central elements of the definition of private household}

The ESS is currently the most methodically controlled survey. Having shown that, despite definition guidelines, each country participating in the ESS - and indeed each linguistic group in the participating countries - uses its own definition of private household, we now turn our attention to the definitions of household employed by the national statistical offices in Europe.

Almost every country defines private household in a different way. A closer look at the various definitions of private household reveals four separate elements:

- common housekeeping in a financial sense

- common housekeeping in an organisational sense

- co-residence

- family

The operationalisation of the housekeeping dimension yields ten categories, five for the superordinate concept of housekeeping in a financial sense and five for the concept of housekeeping in an organisational sense, thereby providing a multifacetted picture of a private household. The operationalisation of the residential dimension also yields five categories. Family can be operationalised in two ways: 
firstly via the degree of legal relationship by blood, marriage etc, and secondly via affective ties. Table 1 shows the 17 categories which can be extracted from the definitions given above.

Table 1: Dimensions for categories of private household-concepts used in national official statistics.

Dimension

1. Housekeeping financial:

1.1

1.2

1.3

1.4

1.5

2. Housekeeping organisational:

2.1

2.2

2.3

2.4

2.5

3. (Co-)Residence

3.1

3.2

3.3

3.4

3.5

4. Family

4.1

4.2
Category

share common budget

share income

share expenses

share costs of living (partly or in full)

contribute jointly to essentials of living

common housekeeping

common living room

share food

share meals: a) daily / b) at least once a week

common living arrangements

live together

share a dwelling

have the same address

the same address in the population register

the address where most nights are spent

degree of legal relationship by blood, marriage, adoption or guardianship affective ties

Table 2 shows the way nine European countries combine the elements listed in Table 1 to produce definitions of private household. For a complete list of the national household definitions of the 27 EU member states as well as the definitions used by Switzerland, Norway and EUROSTAT, see Hoffmeyer-Zlotnik and Warner, 2008.

Where a pair of categories (one from the housekeeping dimension and one from the residential dimension) are used for categorisation purposes, there are 50 possible category pairs. If one subsumes under co-residence all the categories 
which can be paraphrased using the term "the same address", this leaves 30 pairs of categories. None of these pairs is used by more than two countries in their national definition. Even when the 10 categories on the housekeeping dimension are subsumed under the two categories common housekeeping in a financial sense and common housekeeping in an organisational sense, this leaves six matrix cells, of which only one has four entries.

Table 2: National definitions of private household in nine selected European countries.

\begin{tabular}{|c|c|c|}
\hline Country & Categories & included \\
\hline all except Italy & & $\begin{array}{l}\text { all persons living alone; } \\
\text { where there is more than one } \\
\text { person, irrespective of whether } \\
\text { related or not the defining } \\
\text { categories employed are: }\end{array}$ \\
\hline Denmark & 3.4 & registered at the same address \\
\hline \multirow[t]{2}{*}{ England } & $2.4 a+3.3$ & $\begin{array}{l}\text { share meal (daily) plus living } \\
\text { together }\end{array}$ \\
\hline & or: $2.2+3.3$ & $\begin{array}{l}\text { alternatively: common living } \\
\text { room plus } \\
\text { same address }\end{array}$ \\
\hline France & 3.2 & share a dwelling \\
\hline Germany & $1.1+3.1$ & $\begin{array}{l}\text { common budget and live } \\
\text { together }\end{array}$ \\
\hline Italy & 4 & $\begin{array}{l}\text { family (irrespective of common } \\
\text { dwelling) }\end{array}$ \\
\hline Luxembourg & $2.5+3.2$ & $\begin{array}{l}\text { common living arrangements } \\
\text { and share dwelling }\end{array}$ \\
\hline \multirow[t]{2}{*}{ Portugal } & $1.1+3.2$ & $\begin{array}{l}\text { share common budget and share } \\
\text { dwelling }\end{array}$ \\
\hline & $1.3+3.2$ & $\begin{array}{l}\text { alternatively: share expenses } \\
\text { and share dwelling }\end{array}$ \\
\hline Switzerland & $3.2+4.1$ & $\begin{array}{l}\text { share a dwelling plus nuclear } \\
\text { family or not married couple }\end{array}$ \\
\hline$\underline{\text { Slovenia }}$ & $1.2+3.1$ & share income and live together \\
\hline
\end{tabular}

When one also considers all those countries that define private household using only one category, it becomes evident that the number of necessary definitions cannot be reduced to a small figure. In reality, diversification is even greater because the 17 categories already represent subsumptions, as can be seen when one compares Greece and England. While both countries define the dimension "housekeeping organisational" via "shared meal", England uses the 
Juergen H.P. Hoffmeyer-Zlotnik and Uwe Warner

restricting temporal criterion "one common meal a day" while Greece uses the criterion "one common meal a week".

\section{The structures underlying the individual definitions of private household}

Having determined that the diversity of the definitions of private household cannot be reduced by standardisation, we shall now endeavour to uncover the structures which underlie the definitions in order to determine whether it is possible to harmonise the term private household. For this purpose, we shall limit the range of private household definitions to those of six countries, each representing a different definition type: Denmark, England, France, Germany, Italy and Luxembourg. Firstly, we shall determine what types of household are covered by the respective definitions. In a second step we shall use data from the European Community Household Panel (ECHP) and the European Social Survey (ESS) to uncover the structures concealed in the empirical data and to investigate whether these differ from the expected structures.

\subsection{Theoretically possible private household structures}

Since population registers are address-based, the address as a defining element of private household is primarily used by those countries that have a register-based census. When the address is a defining element of private household the persons constituting a household may be spread across several dwellings located at the same address. Where the dwelling, as opposed to the address, is a defining element, the number of persons constituting a household is restricted to those who share a common dwelling unit entrance door. Both the address and the dwelling are clearly defined units to which a number of persons can objectively be assigned. However, a private household which is defined via a spatial unit can be further specified using an additional restricting criterion.

Most countries' definitions feature both a spatial and an economic criterion. Two possibilities come into question:

a) different monetary units, defined in a way which is meaningful in the country concerned and

b) different organisational units, also defined in a country-specific way.

Living together and common housekeeping define in a very exact way the group which constitutes a private household. However, living together, determined by a common address, although clearly defined and delimitable, is more difficult 
to capture empirically than where it is defined in terms of the spatial unit "dwelling".

Except in the case of an exclusively spatial definition in terms of an entry in an address-based population register, the assignment of temporarily absent or present persons to a household represents a problem. Their inclusion usually requires a second criterion, for example economic dependence. As an alternative to a second criterion, the household definition can be supplemented by instructions which describe how specific groups should be dealt with. Persons who are difficult to assign include trainees, students, boarding school pupils, conscripts and those doing civilian service, weekly commuters, workers absent from home on construction jobs and seasonal workers. The temporary absences of these groups vary in length and interval.

The definitions of private household in the selected countries differ considerably from one another and, therefore, provide an overview of the range of criteria employed. Denmark takes the address and France the dwelling as the central defining element. In addition to the spatial aspect (address or dwelling), Germany, England and Luxembourg use a further criterion to delimit common housekeeping. And Italy defines private household in terms of the family (see Table 2).

Denmark defines household in terms of the criterion registered at the same address (Statistics Denmark). This means that, depending on the size and the partitioning of the house, there can be several dwellings at one address. Not all population registers are dwelling-unit-based. Therefore, in a house with several dwellings, the assignment of persons to a particular dwelling unit is only possible if a register of dwellings is available. The Danish definition neither distinguishes between address and dwelling unit nor does it equate the two. As a result, not only do the residents of a shared dwelling which is partitioned and rented out room by room become a dwelling-share (with common living and housekeeping arrangements) but also house communities of all kinds (all residents of a house irrespective of the number of dwelling units) become private households. The assignment of boarding school pupils, students or seasonal workers to private households is done on the basis of population register data.

- Several dwellings = one household;

- connecting element is the common address;

- the number of persons can be large;

- absent pupils, students and seasonal workers are counted in.

France defines household in terms of sharing the same dwelling, thereby limiting it to one dwelling (Centre Maurice Halbwachs). All those residing in the dwelling are assigned to one private household. Since the criterion which specifies the household group is the entrance door to the dwelling, the scope which the French definition offers is smaller than that which the Danish definition would 
permit, given comparable cultural conditions. However, in France too, no distinction is made between a partitioned dwelling rented out room by room and a dwelling-share with common housekeeping. The assignment of boarding-school pupils, students or seasonal workers to private households requires a second criterion which specifies the minimum periods of absence permitted.

- One dwelling = one household;

- connecting element is the common dwelling;

- the number of persons may go beyond members of economic units;

- absent pupils, students and seasonal workers are not included in the household.

Luxembourg defines household in terms of the sharing of the same dwelling and common living arrangements (STATEC, 2003). This means that household is first of all restricted to a dwelling. Within the dwelling, the defining criterion is common living arrangements or membership of a household community. For example, there could be several such communities in a shared dwelling which could each be classified as private households. Since common living arrangements have a large subjective component, a dwelling-share with common housekeeping may be perceived differently depending on the individual resident's point of view. Depending on the prevailing atmosphere, a shared dwelling with a common entrance door may, in one case, constitute a number of small households and, in another instance, it may represent a single household. Weekly commuters are assigned to the household, whereas the classification of boarding school pupils, students and seasonal workers as members of this type of private household depends on the person's self-assignment to the household community.

- One dwelling = one or several households;

- connecting element is the subjective perception of belonging to a household community within a dwelling;

- while the number of household members is restricted via common living arrangements and co-residence, it is not clearly delimited;

- the inclusion of absent pupils, students and seasonal workers depends on their self-assignment as members.

England defines household in terms of the same address and a daily shared meal or, alternatively, a common living room (Thomas, 1999). As a result, a household is first of all restricted to an address. As shown in the case of Denmark, such a household can comprise several dwellings. It is further restricted by the criterion one shared meal daily (or a common living room). A daily shared meal presupposes common housekeeping and a regular daily routine. What connects the members of the household is not a common entrance door to the dwelling but rather the shared regular daily routine. The common living room also supports this view, implying as it does joint social activities. Therefore, a private household can 
be spread across more than one dwelling on condition that the dwellings are located at the same address and that the various dwelling entrance doors do not interfere with regular common housekeeping. Boarding school pupils, students and seasonal workers are not included in the household if they do not participate in the daily routine.

- One or more dwellings = one household;

- connecting element is regular common housekeeping at a shared address;

- the number of persons is narrowly restricted by the dwelling and regular housekeeping criteria.

- absent pupils, students and seasonal workers are not included.

Italy defines household in terms of the family, irrespective of a common dwelling (Istat, 2001). This means that, irrespective of whether it lives in a selfcontained dwelling, the family is, on the one hand, defined via the degree of legal relationship by blood, marriage etc. On the other hand, affective ties determine inclusion or exclusion. Neither operationalisation of family is precise. As a rule, the family concept which serves as a synonym for household implies spatial proximity and is based on the idea of the atrium where a group delimited by family and affective ties lives together in the immediate vicinity of each other. However, absent pupils, students and seasonal workers are assigned to the household as long as they are emotionally included in the family. Since the group of household members is more or less subjectively defined, the group size cannot objectively be determined. Although this household definition is not dependent on the dwelling or even on spatial proximity, even in Italy modern housing construction exercises a considerable influence on the size of the household group.

- One or more dwellings = one household;

- besides legal family relationship, the connecting element is the existence of affective ties or economic dependence;

- because of the subjective nature of the definition and the possible spread across various spatially distant dwellings, the number of household members is very open-ended;

- as a rule, if not emotionally excluded, pupils, students and seasonal workers are considered members of the household.

As can be seen from the above, every definition can embody a different private household composition. And the less criteria employed in the definition, the more imprecise the household composition is. It is true that the bulk of households will not differ significantly from each other across cultures, at least not where assignment is carried out using two criteria. The widespread standardisation of urban residential construction in Europe alone sees to that. Nonetheless, to ignore possible differences in household composition represents a violation of comparability rules. 


\subsection{Private household structures observed in surveys}

The ECHP8 data (see Table 3) clearly indicate that different household sizes exist and that they increase in size from country to country in the expected direction. Nonetheless, it is not possible to infer that the difference in average household sizes is due to the influence of the definition of private household, because household size is not only influenced by the definition but also by culture. As can be seen from the household composition in ESS (see Table 3), in France (48\%) and Italy (49\%) the proportion of households with children is particularly large, while it is relatively small in Luxembourg (26\%). Compared to other countries, almost twice as many respondents live with at least one parent in Luxembourg $(27 \%)$ and Italy $(25 \%)$. In Luxembourg (19\%) and Italy $(20 \%)$ too, the proportion of households in which other relatives and nuclear family live is at least twice as high as in the other countries. Table 3 clearly shows that the proportion of households featuring persons unrelated by blood, marriage etc is very low, with a maximum of $4 \%$ in the United Kingdom and a minimum of $1 \%$ in France.

Table 3: Person type in the household (ESS), in \%, and average number of persons in Household (ECHP wave 8) for the countries DK, FR, LU, UK, IT.

\begin{tabular}{|l|r|r|r|r|r|}
\hline & DK & FR & LU & UK & IT \\
\hline average no. of persons & 2.4 & 2.6 & 2.5 & 2.3 & 2.9 \\
\hline person type & \multicolumn{5}{|l|}{} \\
\hline lone person & 18 & 13 & 12 & 17 & 9 \\
\hline partners & 68 & 69 & 58 & 62 & 61 \\
\hline child(ren) & 35 & 48 & 26 & 35 & 49 \\
\hline parents & 8 & 12 & 27 & 13 & 25 \\
\hline other relatives & 5 & 9 & 19 & 11 & 20 \\
\hline not related & 2 & 1 & 2 & 4 & 2 \\
\hline
\end{tabular}

Data: Persons type: ESS Round 1, Average no. of persons: ECHP Wave 8, authors' own calculations

A typification of the persons resident in the respondent households in ESS, Round 1, shows clearly that the great majority of households comprise members of the nuclear family, in other words partners, children and parents, and siblings. The latter are probably quite often the persons behind other relatives (the population consists of persons aged over 18). It is interesting to note that in Denmark, the United Kingdom and Italy non-relatives in the sense of dwelling-shares with common housekeeping arrangements are most often to be found in two-person households (in Italy in two or three-person households), whereas in Luxembourg they are most often found in large households with five or more persons. 


\subsection{Different definitions of private household held by the various participants in a survey}

In the research process, it is generally assumed that all participants in a survey (researchers, interviewers and target persons) define private household in exactly the same way - at least provided they share a common culture. However, this assumption must be critically examined because, even in a national context, it is likely that, in the case of a tacitly understood household concept, researchers, interviewers and respondents nonetheless have different definitions and, accordingly, different perceptions of household composition. Indeed, even among respondents, there is probably no consensus as to what household means. Despite this, social research surveys often fail to provide any definition of the household concept.

If we assume that researchers adhere to the official definition used by their national statistical office, then what must be investigated are the elements of the definition held by respondents and interviewers. To this end, we conducted a survey of both these groups. First of all, three different sub-populations of survey target persons - students, academics and a random selection of citizens of the city of Mannheim - were asked the following questions:

- What do you understand by the term household?

- What persons are part of your household? If you are a student, then please give these details for your parents' household.

- Why are these people included in the household?

- Where do the persons whom you include in your household usually live? Do they all live in the same dwelling? Or in two neighbouring dwellings? Or in a house with various different dwellings? Or are they spread across a greater distance?

- If you are a student, what is your situation? Of what household do you consider yourself a member? Of your own household? Or of your parents' household?

- Please give reasons for your self-assignment.

The following elements of a conceptualisation of household emerge from the replies given by the potential-respondent group which comprised 46 students of Gießen and Mannheim Universities and 25 academics resident in Mannheim:

- The first element is the dwelling unit. This is described in terms of living under one roof, having an entrance door and/or a rental agreement, representing a self-contained living situation.

- The second element is the dwelling-share with common housekeeping, described in terms of living together with common housekeeping or common housekeeping. Dwelling-shares for convenience purposes is the term often used to describe such living arrangements. 
- The third element is the family. Being related to each other and living together in one house are the characteristics used to describe family; this often means first-degree family.

- As a fourth element, some respondents stress affective ties which are also described using the words being very close.

- A fifth element is provided by the emphasising of common activities. The common aspect is broken down into three dimensions:

- common housekeeping with the emphasis on shopping, kitchen, cooker, fridge, washing machine. Especially for students, having their own washing machine is what constitutes having their own household.

- working together with the emphasis on sharing housework;

- common living arrangements with the emphasis on eating and sleeping.

The permanent or common main place of residence is also mentioned in this regard.

- As a sixth element, financial dependence is emphasised. This is expressed in terms of common financial budget, the sharing of the costs of living, the sharing of rent, and the maintenance of a common household kitty

- The seventh element cited is common planning or life planning. This not only entails taking care of each other, sharing tasks and responsibilities, but also the sharing of rooms and daily consumer goods. Shared meals are also emphasised.

- The eighth element is residence. The important feature here is either the registration as principal residence or the same address. The same key to the dwelling is also used as a synonym for the address. With regard to the time dimension of the household concept, the length of stay is given as always, mostly, or frequently.

A standardised definition cannot be constructed using these eight elements. They diverge to a considerable extent from the definition employed by the statistical offices, and, therefore, we surmise that they also deviate from the definition held by researchers.

When asked whether a household could be spread across several dwellings, respondents argued as follows:

Of course a household could encompass several dwellings where the additional dwellings served to enlarge the original one, for example in the case of a so-called "granny-flat" or two adjacent apartments with a connecting door. However, the precondition in all such cases is that the dwellings in question should all be in the same house.

Several spatially-distant dwellings are considered by some respondents to be one household: 
1) where cohabitation in a long-distance relationship is defined in terms of affective ties;

2) in the case of persons such as students who, as a result of financial dependence on their parents, become members of two households, the parental and their own;

3 ) in the case of persons who pay a financial contribution to and/or contribute to the (house)work in two spatially-distant dwelling units.

The assigning of a person to two different households is supported by respondents when, for example, students assign themselves to their own household while, at the same time, their parents consider them to be members of the parental household. For seasonal workers and weekly commuters, the temporary absence from the family household can also lead, in their own perception, to membership of a second household.

The interviewer group comprised 118 telephone interviewers employed by the Institute for Applied Social Sciences GmbH (infas) in Bonn. For our survey they took on the role of respondents and gave their private opinions on the subject of the household.

All things considered, in their role as respondents the interviewers have a lot in common with the potential target persons. They provide a multi-facetted and individually-oriented range of definitions, not one of which coincides with that employed by the German statistical offices. Nor are their definitions geared towards making their task of obtaining field access easier. The interviewers mention the same eight elements as the potential respondents. However, those who are part of a nuclear family with a partner and child(ren) emphasise family as a defining element more frequently than those who are not. On the one hand, family membership is described in terms of family ties or a strong social bond, and, on the other hand, it is defined via participation in family life, raising the children together, and taking care of each other. This group accepts a temporary absence due, for example, to military service or work-related weekly commuting. However, they do not accept households spread across several dwellings. As the great variety of defining elements cited by the interviewers clearly shows, it is essential that researchers precisely define and communicate the household concept to be used in their survey.

Survey researchers and survey data users cannot simply rely on the interviewers' and respondents' knowing what household means in the context of the research question. In the absence of a precise definition explicitly communicated to the survey participants, both interviewers and respondents have to resort to their own individual definitions. 


\section{The influence of the definition on household composition}

The national statistical offices of Italy, Denmark, France, Luxembourg and England each employ very different definitions of "private household". In this chapter we use the example of a fictional extended family to illustrate how strongly the definition of household in these countries affects the composition of the group of people assigned to a household, and how this, in turn, affects the variables "household income" and SES.

\subsection{The influence of the size of private households on total household income}

The following the example of a group of nine people illustrates clearly the connection between household composition (number of persons in/assigned to the household) and the calculation of household income. This connection is due to the fact that household income is dependent on the number of persons that contribute to it and the types of income which these persons contribute. As the example shows, the smaller a household is by definition, the lower the average net equivalised income. Since, however, the poverty line in the EU member countries has been set at less than $60 \%$ of the net equivalised income in the respective country, the national poverty lines can be almost arbitrarily raised or lowered by using the household definition to change household composition.

An exemplary extended family comprises 9 persons:

- a married couple (grandfather and grandmother)

- with two adult sons (one is an uncle, the other is a father)

- of whom one is married (to wife/mother) with three children (children nos. $1,2,3)$;

- the eldest of these children, a daughter, is also married (to son-in-law)

This exemplary extended family is spread across five to six dwellings:

- The grandparents live in their own apartment but in the same house and at the same address as their son and daughter-in-law - the father and mother.

- The father and mother and their youngest child (child no. 3, under 14) live in the one apartment. However, the father is home only at the weekends because his place of work is a four-hour drive from the family dwelling. The father has a secondary residence at his place of work.

- Child no. 1, a daughter, has her own family and lives together with her husband - the son-in-law.

- Child no. 2 (14 and over) is a student and lives at the place of study in a student residence. 
- The uncle has his own dwelling in the same city as the grandparents but in a different quarter.

Looking at this family in terms of the household definitions in the five countries selected to show the range of definitions in use, one obtains the following picture (Hoffmeyer-Zlotnik and Warner, 2008: 54):

- The Italian definition assumes that those who are emotionally included in the family are members of the household, irrespective of they live in the same dwelling or have the same address (Istat, 2001). So, employing the Italian definition, we have a nine-persons household spread across four dwellings.

- The Danish definition includes in the household all persons registered at the same address (Statistics Denmark). In this case, the extended family is spread across three households. The core household comprises six persons: The grandparents in a so-called granny flat, the mother and father (since the family dwelling is registered as the father's primary residence), child no. 3 (lives with the parents) and child no. 2 for whom the student residence is not the primary residence.

- The French definition, based on a common dwelling (Centre Maurice Halbwachs), spreads the extended family across four households. The core household comprises the father and mother and children nos. 2 and 3

- Luxembourg's definition which restricts household to living together in a common dwelling (STATEC, 2003), spreads the extended family across 5 households. Only the father, the mother and child no. 3 live in the core household.

- On the one hand, the criterion daily shared meal in England's definition of household very narrowly restricts household size (Thomas, 1999). On the other hand, however, the use of the criterion same address instead of same dwelling makes it broader again. As a result, there are several possible configurations for the family in our example: What we actually have here are six households, with the core household comprising two persons, the mother and child no. 3. However, if the mother regularly cooks for the grandparents, then we could also have a four-person household spread across two dwellings at the same address. As an alternative to the sharedmeal criterion, the English allow a common living room (Thomas, 1999). Under this condition, the father could also be included in the household and the grandparents would constitute their own household.

Table 4 summarises by country the number of households across which the nine members of the fictional extended family are spread. It also shows how many of these persons belong to the core household in each case. 
Table 4: Number and size of households as a function of household definition.

\begin{tabular}{|l|c|c|}
\hline Country definition & No. of households & Persons in the core household \\
\hline Italy & 1 & 9 \\
\hline Denmark & 3 & 6 \\
\hline France & 4 & 4 \\
\hline Luxembourg & 5 & 3 \\
\hline England & $6(5)$ & $2(4)$ (shared meals) \\
\hline
\end{tabular}

Table 5 summarises the household compositions of the nine members of the extended family in the four countries in question. It shows by country which of the nine persons live in the same household. Since each person is assigned an income and this income is assigned an OECD equivalised weight depending on the household to which they belong, it is possible to determine the average net equivalised income per country.

Table 5: Composition and average income of households in selected countries.

\begin{tabular}{|c|c|c|c|c|c|}
\hline \multirow[t]{2}{*}{ Persons } & \multirow{2}{*}{$\begin{array}{r}\text { income } \\
\text { of person }\end{array}$} & \multicolumn{4}{|c|}{ Equivalence scale } \\
\hline & & Italy & Denmark & France & UK \\
\hline uncle & 1500 & 0.5 & 1.0 & 1.0 & 1.0 \\
\hline grandfather & 1800 & 0.5 & 0.5 & 1.0 & 1.0 \\
\hline grandmother & 0 & 0.5 & 0.5 & 0.5 & 0.5 \\
\hline father & 2500 & 1.0 & 1.0 & 1.0 & 1.0 \\
\hline mother & 500 & 0.5 & 0.5 & 0.5 & 1.0 \\
\hline child no. 3 & 600 & 0.3 & 0.3 & 0.3 & 0.3 \\
\hline child no. 2 & 1000 & 0.5 & 0.5 & 0.5 & 1.0 \\
\hline child no. 1 & 400 & 0.5 & 0.5 & 0.5 & 0.5 \\
\hline son-in-law & 2500 & 0.5 & 1.0 & 1.0 & 1.0 \\
\hline
\end{tabular}

\begin{tabular}{|c|c|c|c|c|}
\hline \multirow[t]{2}{*}{ Household No. } & \multicolumn{4}{|c|}{ Equivalence household income } \\
\hline & Italy & Denmark & France & UK \\
\hline HH 1 & 2,250 & 1,500 & 1,500 & 1,500 \\
\hline HH 2 & & 1,939 & 1,200 & 1,200 \\
\hline HH 3 & & 1,933 & 2,000 & 2,500 \\
\hline $\mathrm{HH} 4$ & & & 1,933 & 846 \\
\hline HH 5 & & & & 1,000 \\
\hline HH 6 & & & & 1,933 \\
\hline & & & & \\
\hline $\begin{array}{l}\text { Average } \\
\text { Household } \\
\text { Income }\end{array}$ & 2,250 & 1,791 & 1,658 & 1,497 \\
\hline
\end{tabular}

The more households into which the fictional extended family is divided, the lower the average household income is. However, if the average household income 
in a country drops, so too does its poverty line. Viewed in this light, the definition of the household concept helps to raise or lower the national poverty line.

\subsection{The socio-economic status of the household members}

In social science analyses, it is now customary to assign all household members the socio-economic status of the member with the highest status. In the ESS, data on occupations and jobs are collected only in respect of the interviewee, his/her partner and their parents. Therefore, we have to resort to the above-mentioned fictional example to illustrate the dependence of status on household composition. The measure of SES we use is the International Socio-Economic Index of Occupational Status (ISEI) (Ganzeboom et al, 2003) which is based on the 1988 version of the International Standard Classification of Occupations (ILO 1990).

In Italy, despite the fact that they are spread across 6 different dwellings, all 9 persons belong to one household. The father, as the "pater familias", determines the status of all the household members. In Denmark, the 9 persons are spread across three addresses, not including the father's secondary residence at his place of work and that of child no. 2 at her place of study. The Danish definition thus yields three households (see Table 5). As can be seen from Table 6, the persons who determine the SES of these three households are the uncle, father and son-inlaw respectively. In France, the 9 persons are spread across 4 households defined in terms of a common dwelling. The French definition therefore excludes the grandparents from the father's household and assigns them a household of their own. In Luxembourg, household is defined in terms of living together in a common dwelling. As a result, the 9 persons are spread across 5 households. In England, which defines household in terms of a common meal a day under one roof, the 9 persons are spread across 6 households.

In all five countries, the person with the highest SES determines the status of the whole household. Where child no. 2, a student with a dwelling at her place of study, is assigned her own household (for example in Luxembourg and England), then this household is assigned the father's status because there is no separate SES for students.

The larger the household, the greater is the probability that it will contain a person with a high SES who will raise the status of the other members. The smaller the households become, the greater the likelihood that lower status persons determine the status of the household. 
Table 6: Composition and socio-economic status of households in selected countries.

\begin{tabular}{|c|c|c|c|c|c|c|c|c|c|c|c|}
\hline \multirow[b]{2}{*}{ Person } & \multirow[b]{2}{*}{ ISCO88 } & \multicolumn{2}{|c|}{ Italy } & \multicolumn{2}{|c|}{ Denmark } & \multicolumn{2}{|c|}{ France } & \multicolumn{2}{|c|}{ Luxemb } & \multicolumn{2}{|c|}{ UK } \\
\hline & & $\mathrm{HH}$ & ISEI & $\mathrm{HH}$ & ISEI & $\mathrm{HH}$ & ISEI & $\mathrm{HH}$ & ISEI & $\mathrm{HH}$ & ISEI \\
\hline uncle & 7422 & $\mathrm{HH} 1$ & 33 & $\mathrm{HH} 1$ & 33 & $\mathrm{HH} 1$ & 33 & $\mathrm{HH} 1$ & 33 & $\mathrm{HH} 1$ & 33 \\
\hline $\begin{array}{l}\text { gdfather } \\
\text { gdmother }\end{array}$ & $\begin{array}{l}8285 \\
\text { housew }\end{array}$ & & 30 & $\mathrm{HH} 2$ & 30 & $\mathrm{HH} 2$ & 30 & $\mathrm{HH} 2$ & 30 & $\mathrm{HH} 2$ & 30 \\
\hline father & 3112 & & 45 & & 45 & $\mathrm{HH} 3$ & 45 & HH3 & 45 & $\mathrm{HH} 3$ & 45 \\
\hline $\begin{array}{l}\text { mother } \\
\text { child no. } 3\end{array}$ & $\begin{array}{l}7331 \\
\text { school }\end{array}$ & & 29 & & 29 & & 29 & & 29 & $\mathrm{HH} 4$ & 29 \\
\hline child no. 2 & study & & & & & & & $\mathrm{HH} 4$ & $(45)^{\star}$ & $\mathrm{HH} 5$ & $(45)^{\star}$ \\
\hline child no. 1 & housew & & & $\mathrm{HH} 3$ & & $\mathrm{HH} 4$ & & $\mathrm{HH} 5$ & & $\mathrm{HH} 6$ & \\
\hline son-in-law & 2142 & & 69 & & 69 & & 69 & & 69 & & 69 \\
\hline
\end{tabular}

* Given that child no. 2 is a student, the parental status is taken as the student's socio-economic status of the household

\section{Harmonisation of the household concept for purposes of international comparison}

When it comes to international comparisons of survey findings, it is necessary to define explicitly what is meant by (co-)residence and common housekeeping because, to a greater or lesser extent, each country has its own definition of household and each of these definitions can entail a different group composition or size. In international comparisons, it is also important to list the groups of persons who should be included or excluded because researchers, interviewers and respondents are also influenced by their own understanding of household and by their culture.

The list of the household members to be regarded as a unit in accordance with the criteria of co-residence and common housekeeping firstly details all those who are all too often forgotten, such as children, especially infants. Furthermore, persons who are temporarily absent due to education, training or work, or persons who are temporarily away from the household because of illness, holidays or other reasons are assigned to the household. The maximum permissible length of the absence -6 months - is based on the period used in many countries' definitions. In 
the next step, resident domestic staff, au-pairs, nursing staff and care-givers are classified as household members. All family members or former household members who live in collective accommodation are excluded, as are those who have been absent for longer than six months and persons who are present temporarily such as visitors. It is true that this list represents a massive intervention in the definition because temporarily absent persons are re-assigned to the household. Nonetheless, only a definition like this, which can be accepted by as many cultures as possible, allows for comparative analysis.

Finally, we now endeavour to assign the number of persons listed to dwelling units because the household definition is not always restricted to one dwelling. Socalled self-contained "granny flats" adjacent to the main dwelling which could be occupied by children or parents are common. Where household is defined in terms of a dwelling entrance door, these flats should be regarded as separate dwelling units. Weekly commuters should also be included in the central household. This can lead to a problem where the survey population is defined in terms of the resident population because, in this case, weekly commuters and students can be located in two places and included in two households. However, this dilemma can be solved only by means of an appropriate definition of the survey population.

Questionnaire questions for a harmonised and comprehensive survey of the private household :

Question 1: A household consists of all persons living together with common housekeeping.

Note to the questionnaire designer: In the own national context please replace "housekeeping" by your national operationalisation of household organisation.

\begin{tabular}{|l|l|}
\hline \multicolumn{1}{|c|}{ Phese are ... } & $\begin{array}{l}\text { Number } \\
\text { persons }\end{array}$ \\
\hline yourself & 1 \\
\hline all other adults living in this household permanently & \\
\hline all children, including infants, living in this household permanently & \\
\hline $\begin{array}{l}\text { all persons in education or training, such as boarding-school pupils and students, } \\
\text { who are temporarily absent at the moment }\end{array}$ & \\
\hline $\begin{array}{l}\text { persons absent at the moment because of their job, such as weekly commuters, } \\
\text { seasonal workers and persons away on construction jobs }\end{array}$ & \\
\hline persons absent because of community and civilian service or military service & \\
\hline persons absent for a maximum of six months because of sickness or holidays & \\
\hline $\begin{array}{l}\text { persons absent for a maximum of six months because of other reasons, such as } \\
\text { imprisonment on remand }\end{array}$ & \\
\hline also included are resident domestic staff, au-pairs and caregivers/nurses & \\
\hline
\end{tabular}

Subtotal (a) please fill in the number of persons 


\begin{tabular}{|l|l|}
\hline $\begin{array}{l}\text { Persons not counted as household members are ... } \\
\text { Please fill in the number of persons }\end{array}$ & $\begin{array}{l}\text { Number } \\
\text { persons }\end{array}$ \\
\hline regular professional soldiers and policemen living in barracks & \\
\hline family members living in nursing homes and homes for the elderly & \\
\hline persons absent for more than six months & \\
\hline visitors, including long-term visitors & \\
\hline
\end{tabular}

Subtotal (b)

please fill in the number of persons

Note to the interviewer: Please double check the first list should not contain person counted in the second list

In your household life in total persons. Please fill in the correct number of household members

Question 2: $\quad$ Is this household spread over more than one dwelling?

yes no

If yes:

Question 2a: How many different dwellings?

Please, fill in the number of dwellings:

Question 2b: In this dwelling, how many people share common housekeeping?

Please count again all persons including children and persons absent for a maximum of six months because of work, education, illness, holidays, civilian or military service, imprisonment etc.

Please enter the number of persons:

\section{Conclusion}

When no uniform definition of household is specified during the survey, then the participating respondents, interviewers and researchers end up talking at cross purposes - even at national level. This is due to the fact that every individual has his or her own idea of what constitutes a private household. Our survey of potential respondents and interviewers revealed that the list of elements used to construct these personal definitions is very long indeed. These elements range from "dwelling unit" through "common housekeeping", "common activities" and "common living arrangements" to "family" and "affective ties". "Common housekeeping", as the more general term, can be defined in a very idiosyncratic 
way. Moreover, depending on the individual living situation, a household can be spread across more than one dwelling.

Depending on

a) the elements included in the definition,

b) the extent to which the persons included in the household may be distributed spatially, and

c) the extent to which the group defines itself via affective ties, very different household compositions emerge - even at national level.

Moving on to the cross-national level, comparability is further hampered by the fact that the various elements used to construct the definition of household are defined in a culture-specific way. For example, the definition of "common housekeeping" varies considerably from country to country. The national definitions cited earlier show how a country's definition of private household influences the household constellations of a given group of people. Taking a fictional extended family as an example, we demonstrated how, under certain circumstances that remain constant across all the countries analysed, this group can end up being assigned to one household or being spread across as many as six households, depending on the definition employed by the national statistical office in question. Hence cross-national comparison is rendered impossible. The definition of household can even serve to raise or lower the national poverty line. By the same token, the socio-economic status of the persons assigned to a household varies depending on how household is defined.

Comparison is possible only where a definition of private household is specified. This definition must be clearly understood and comparably interpreted by all respondents, interviewers and researchers so that the concept that is intended to be measured is actually measured (face validity). However, in the case of cross-national comparison, a culture-specific definition of "common housekeeping" can be accepted. To make the respondent's task easier, lists of inclusion and exclusion criteria specifying who may and may not be included in the observed household should be drawn up. Only with these lists and a specified and generally understandable definition of "private household" can crossnationally comparable household compositions be arrived at (measurement validity). Whether the persons assigned to a private household may be spread across more than one dwelling remains open. Since several definitions of "housekeeping" allow this, the number of dwellings across which a household is spread must also be recorded, as must the household members who can be found at the contact address.

In survey research, the definition of private household continues to regarded as "unproblematic". After all, everyone knows what "household" means! This misconception leads to a wide range of incompatible definitions and these, in turn, result in a multitude of household compositions. Therefore it is essential that the private household concept be defined in an understandable and authoritative way 
Juergen H.P. Hoffmeyer-Zlotnik and Uwe Warner

for all survey participants. The instrument for the measurement of "private household" presented here is one which can be used anywhere in Europe and which yields comparable data.

\section{References}

[1] Bundesamt für Statistik (2008): Definitionen. Neuchatel, http://www.bfs.admin.ch/bfs/portal/de/index/infothek/definitionen.html (07-24-08).

[2] Centre Maurice Halbwachs (2008): UMR 8097 (CNRS-EHESS-ENSUniversité de Caen) http://www.cmh.ens.fr/acsdm2/glossair.php (07-24-08).

[3] Commission Regulation on sampling and tracing rules (2003): $N^{\circ} 1982 / 2003$ of 21 October 2003, §7.4.

[4] European Commission (2001): Demography, Education and Health in EU SILC: An overview of key issues and the proposed target variables. Meeting of the Working Group on Statistics on Income and Living Conditions (EUSILC) European Community Household Panel (ECHP) Luxembourg, 26-27 April 2001 EU-SILC 31-1/01.

[5] European Social Survey(ESS). www.europeansocialsurvey.org/ (07-24-08).

[6] European Social Survey (2002a): ESS1-2002 Appendix A3_e6: Variables and Questions. www.europeansocialsurvey.org/ (07-24-08).

[7] European Social Survey (2002b): Project Instructions (PAPI) ESS Document date: 15/07/02, Autumn 2002.

[8] European Social Survey (2003a): ESS1-2002 Questionnaires and other fieldwork documents.

http://ess.nsd.uib.no/index.jsp?year=2003\&module $=$ questionaires $\&$ module $=q$ uestionaires\&country=Select+Country (07-24-08).

[9] European Social Survey (2003b): ESS1-2002 Questionnaires and other fieldwork documents. Documents for Portugal. Instruções de apoio ao preenchimento do questionário".

http://ess.nsd.uib.no/index.jsp?year=2003\&module=questionaires\&module $=$ questionaires $\&$ country $=\mathrm{PT}(07-24-08)$.

[10] European Social Survey (2003c): European Social Survey, Round 1, Technical Report. Chapter 2: Sample. www.europeansocialsurvey.org/ (0724-08).

[11] Eurostat (1996): The European Community Household Panel (ECHP). Volume 1. Survey methodology and implementation. Luxembourg: Survey Questionnaires.

[12] Ganzeboom, Harry B.G. and Treiman, Donald. J. (2003): Three Internationally Standardised Measures for Comparative Research on 
Occupational Status. In J.H.P. Hoffmeyer-Zlotnik and Ch. Wolf (Eds.): Advances in Cross-National Comparison. A European Working Book for Demographic and Socio-Economic Variables (pp.159-193). New York: Kluwer Academic/ Plenum Publishers.

[13] Hoffmeyer-Zlotnik, J,H.P. (2008): Harmonisation of demographic and socioeconomic variables in cross-national research. BMS 98, April 2008, 5-24.

[14] Hoffmeyer-Zlotnik, J.H.P. and Warner, U. (2008): Private Household Concepts and their Operationalisation in National and International Social Surveys. GESIS-Forschungsberichte. Survey Methodology. Vol 1.

[15] ILO (1990): International Standard Classification of Occupations, ISCO-88. Geneva: ILO.

[16] Instituto Nacional de Estatística (2003): Aprovado pelo Conselho Superior de Estatística desde. (04-11-03).

[17] International Social Survey Programme (ISSP) www.issp.org/ (07-24-08).

[18] Istituto Nazionale di Statistica (ISTAT) (2001): 14 Censimento generale della popolazione e censimento generale delle abitazioni-2001.

[19] National Statistical Service of Greece (2003): Population and Housing Census 2001. Definitions - Concepts.

[20] National Statistics(2001): count me in. Census 2001. England Household Form. http://census.ac.uk/guides/Qf.aspx (07-24-08).

[21] OECD Social Policy Division (2008): What are equivalence scales? http://www.oecd.org/dataoecd/61/52/35411111.pdf (07-24-08).

[22] Slovenia (1997): Survey Information. www.lisproject.org/techdoc/si/si97survey.pdf (07-11-07).

[23] STATEC (2003): Recensement de la population 2001. Résultats détaillés. Novembre 2003. Luxembourg http://www.statec.lu (07-24-08).

[24] Statistical Commission and Economic Commission for Europe (UNECE), EUROSTAT, Conference of European Statisticians, OECD (2005): Overview of the efforts underway in the UNECE region to measure emerging forms of families and households. Working Paper No 5. 21 September 2005: 8. unece.org/stats/documents/2005/09/social/wp.5.e.pdf (07-24-08).

[25] Statistics Denmark (2008): Declarations of content: Census of housing, 1st January.

http://www.dst.dk/HomeUK/Guide/documentation/Varedeklarationer/emnegr uppe/emne. $\operatorname{aspx}$ ? sysrid=931 (07-24-08).

[26] Statistisches Bundesamt (1998): Bevölkerung und Erwerbstätigkeit. Fachserie 1, Reihe 3 Haushalte und Familien 1996 (Ergebnisse des Mikrozensus). Stuttgart: Metzler-Poeschel. [StaBA 1998, Reihe 1, Fachserie 3]. 
[27] Thomas, R. (1999): Question Bank Commentary: Household Definition. http://qb.soc.surrey.ac.uk/topics/housedefinition/household definition thomas.pdf (07-24-08).

[28] United Kingdom (1991): 1991 Census: definitions and concepts. http://census.ac.uk/guides/Qf.aspx/1991_Definitions_and_Concepts.pdf (07-24-08). 